\title{
Developing the Estimating Equations for Muscle Power by Analysis of Reliability and Validity on Different Versions of Wingate Anaerobic Test Setting
}

\author{
Bongju Sung ${ }^{1}$, Byounggoo Ko ${ }^{1}$ and Kwangkyu Lee ${ }^{2 *}$ \\ ${ }^{1}$ Korea Institute of Sport Science, Seoul, Korea \\ ${ }^{2}$ Department of Exercise Rehabilitation, Jeonju Kijeon College, Jeonbuk, Korea
}

\author{
Article Info \\ Received 2021.05.14. \\ Revised 2021.06.26. \\ Accepted 2021.07.22. \\ Correspondence* \\ Kwangkyu Lee \\ kwangkyu78@hanmail.net \\ Key Words \\ Wingate anaerobic test, \\ Peak power, \\ Mean power, \\ Power drop rate, \\ Estimating equation
}

PURPOSE The purpose of this study was to develop the estimating equations for 4 types of Wingate Anaerobic test setting. METHODS 80 male elite athletes performed 4 trials of the Wingate Anaerobic test by each type. Subjects were conducted the retest one week later. Data collected from the Wingate Anaerobic test included mean power, peak power, and power drop for 30 s were measured. Coefficient of correlation was used for validity of type 1(DOS version) and the other types(ver. 2.24, 3.3.0, and 3.2.1). Pearson's correlation coefficient was used to examine the reliability of test and retest. Simple regression analysis was used for calculating the estimating equation. RESULTS There was significant correlation for absolute value(Watt, $p<.01)$ and relative value(Watt $/ \mathrm{kg}, \mathrm{p}<.01)$ of mean power, absolute value( $\mathrm{W}, \mathrm{p}<.01)$, relative value(Watt/ $\mathrm{kg}, \mathrm{p}<.05)$, and power drop rate $(\%, \mathrm{p}<.01)$. Test and retest reliability was excellent for all test variables $(p<.01)$. CONCLUSIONS From the all results, the estimating equation was calculated to convert all outputs from each type to the other types of the Wingate Anaerobic test setting. These findings suggest that the estimating equations are compatiable to 4 types of Wingate Anaerobic test setting.

\section{서론}

대부분의 스포츠 종목에서는 단관절 움직임보다는 기초체력과 전문체 력이 복합적으로 발휘될 수 있는 대근육군의 다과절 협응이 경기력의 중 요한 요인으로 거론되고 있다(Bompa, 1999). 특히, 전문체력요인 중에 서 짧은 시간의 움직임이 발생되는 스피드, 민첩성 또는 파워 발현에는 ATP-PCr과 해당작용(glycolytic systems)을 통해 주된 에너지 공급이 이루어지게 된다(Vandewalle et al., 1987; Baker et al., 2010). ATP$\mathrm{PCr}$ 에 의한 에너지 동원은 초기 고강도 활동에서 $100 \%$ 동원이 이루어 지며, 이런 에너지 동원의 최고 지점 도달 시간은 약 2.5 초 정도인 것으 로 보고되고 있다(Baker et al., 2010). 선행연구에서는 경기력을 위한 최고파워 도달 시점은 1 4초 이내인 것으로 나타났으며(Bogdanis et al., 1998), 이후 10초 지점까지 완만하게 감소하는 것으로 보고하고 있 다(Bigland-Ritchie \& Woods, 1984; Vandewalle et al., 1987). ATP$\mathrm{PC}$ 의 점증적 고갈과 동시에 해당과정의 에너지 동원이 이루어지게 되 는데, 해당과정을 통한 에너지 최대 발현 시점은 15 20초이며 30초 이 후 급격한 감소가 나타난다(Beneke et al., 2002; Ren \& Hultman, 1989). 이렇듯 운동 초기 또는 활동이 시작되는 시점부터 30초 지점까
지의 에너지 동원은 $\mathrm{ATP}-\mathrm{PCr}$ 과 해당과정에서 대부분 이루어지고 있음 을 알 수 있으며, 이 두 가지 에너지 체계는 장시간의 고강도 움직임에서 도 에너지 공급에 일부분 관여하기(Baker et al., 2010) 때문에 체내 저 장 수준이 시합의 승패와 밀접한 관련이 있음을 알 수 있다. 또한 무산소 성 에너지 동원 수준을 측정을 통하여 수치화 시킨다면 선수들의 훈련 구성 및 체력 변화에 대한 기초자료로 활용될 것이다. 그러므로 에너지 동원 정도를 관찰하기 위한 전문체력측정은 선수들의 경기력 변화를 관 찰하는데 도움이 될 것이다.

다양한 무산소성 운동능력 측정기기 중에서 무산소성 윈게이트테스 트(Wingate anaerobic test) 방법은 피험자의 무산소성 파워를 측정하 기 위한 일반화된 방법으로(Beneke et al., 2002; Vandewalle et al., 1987), 체중에 따른 운동부하를 기반으로 고정식 사이클 페달을 30초 동안 최대한 회전시킨 후 발생된 토크값으로 무산소성 운동능력을 평 가하는 방식이다(Richmond et al., 2011; Weinstein et al., 1998; Zupan et al., 2009). 에르고미터를 활용한 측정은 종목 특성과 목적에 맞게 상체 또는 하체로 나누어 측정할 수 있으며, 두 방법 모두 체중에 대한 간섭을 최소화 할 수 있기 때문에 결과에 대한 높은 신뢰성을 확보 할 수 있게 된다(Richmond et al., 2011). Zupan et al.(2009)은 윈게 
이트테스트는 무산소성 운동 능력에 대한 가장 신뢰할 수 있는 평가방법 으로 다양한 변인을 통한 선수들의 현재 체력 수준 및 훈련 전 · 후 결과 비교가 가능하며, 측정에 따른 상해를 최소화 할 수 있어 안정성이 확보 된 측정 방법으로 소개하였다. Harvey et al.(2017)은 윈게이트테스트 의 1 회 측정으로 다양한 체력 변인의 관찰이 가능하며, 측정 시간이 짧 아 빠른 회복(6분 이내)을 유도할 수 있어 이후 훈련에 큰 영향이 없는 것으로 보고하였다. 이처럼 윈게이트테스트는 무산소성파워및 지구력 평가에 널리 활용되고 있다. 윈게이트테스트의 측정 변인으로는 평균파 워(mean power;MP), 최고파워(peak power;PP), 파워드롭률(Power Drop rate; PD)등이 있으며(Bar-Or et al., 1980; Bar-Or, 1987; Attia et al., 2014; Laurent et al., 2007), 종목에 따라 다양하게 선택하여 평 가 도구로 활용되고 있다. 그러나 이러한 결과 값의 신뢰도를 확보하기 위해서는 다양한 외생변수(온도, 습도, 측정 시간, 심리, 사전운동)에 대 한 요인들의 통제가 이루어져야 하며(Inbar et al., 1996), 특히, 사전 · 사후에 대한 평가는 처치에 따른 향상도를 관찰하는 것이기 때문에 외생 변수에 대한 통제가 더욱 세심하게 이루어져야 할 것이다. 또한 윈게이 트테스트 기기의 지속적인 성능 개선으로 다양한 버전의 장비가 출시되 었으며, 그로인한 기기별 측정값이 상이하여 일관된 해석에 한계가 있어 왔다. 현재까지 다양한 연구에서 서로 다른 버전의 윈게이트테스트 측 정이 이루어지고 있으며, 이를 근거로 실험에 대한 효과 검증, 훈련 프 로그램 구성 및 향상도 평가의 기초자료로 활용하고 있다(Grant et al., 2014; Kavaliauskas et al., 2015; Raci et al., 2017; Kendall, 2017; Lewis et al., 2017). 그동안 윈게이트테스트의 타당성과 신뢰성이 이미 검증(Bar-Or, 1987)되었음에도 불구하고 각 버전별 결과 값에 대한 동 질성 검증 연구는 미비한 실정이며, 다양한 외생변수를 고려하더라도 장 비 또는 버전의 변화를 고려하지 않은 측정은 사전 또는 사후 값에 대한 신뢰성 확보에 어려움이 있을 것으로 여겨진다. 그러므로 각기 다른 버 전의 측정결과를 기초로 타당도와 신뢰도 검증이 시급하며, 결과 값의 기기별 상호호환이 가능한 추정식 개발이 필요함을 알 수 있다. 이를 통 해 과거와 현재의 윈게이트 결과 값을 표준화해 일관된 해석이 가능할 것으로 기대된다.

그러므로 본 연구에서는 과거부터 현재까지 다양한 연구에서 제시되 고 있는 윈게이트테스트 결과 값을 표준화해 활용할 수 있도록 각 기기 의 버전별 결과 값의 타당도와 신뢰도를 분석하여 상호 변환해 사용할 수 있는 추정식을 개발하는데 그 목적이 있다.

\section{연구방법}

\section{연구대상}

본 연구에서는 $\mathrm{H}$ 대학교 학생들 중 배드민턴(n=15), 레슬링(n=19), 역도 $(n=16)$, 육상 $(n=16)$ 종목의 엘리트 선수 66 명과 국가대표 남자 복싱선

Table 1. Characteristic subjects

$($ Mean \pm SD)

\begin{tabular}{cc}
\hline Variable & Subjects $(\mathrm{n}=80)$ \\
\hline Age $(\mathrm{yrs})$ & $20.4 \pm 0.21$ \\
Height $(\mathrm{cm})$ & $174.8 \pm 6.86$ \\
Weight $(\mathrm{kg})$ & $75.9 \pm 14.86$ \\
BMI $\left(\mathrm{kg} / \mathrm{m}^{2}\right)$ & $27.4 \pm 2.41$ \\
\hline
\end{tabular}

수 14 명을 포함하여 총 80 명을 대상으로 실험을 실시하였다. 진행 방식 은 국내 도입된 윈게이트테스트 장비 중 총 4가지 형태 (Type A: DOS version, Type B: version 2.24, Type C: 3.3.0.0, Type D: version 3.2.1.0)를 이용하여 30초씩 반복측정을 실시하였다. 실험 전 참가자들 에게 실험의 목적과 유의사항에 대해 충분히 설명하였으며, 자발적 참가 동의서를 받았다. 참가자는 실험 전 문진 및 실험에 대한 설문지를 작성 하였으며, 연구의 신뢰도를 검증하기 위해 2 회 반복측정을 하였으나, 참 여인원의 $55 \%$ 인 44 명은 개인사정으로 인하여 재측정하지 못하였고 36 명 만 재측정에 참여하였다. 본 실험은 한국스포츠정책과학원 생명윤리 위원회의 연구승인(KISS-1609-014-01)을 얻었으며, 연구 대상자의 신 체적 특징은 〈Table 1 〉과 같다.

\section{실험설계}

본 연구에서의 실험설계는 〈Fig. 1〉과 같다. 실험 전 연구대상자들의 안 전을 위해 스트레칭 및 준비운동을 실시하였다. 스트레칭은 평소 자신이 운동 전 실시하는 스트레칭 방법으로 10 15분 정도 실시하였으며, 이 후 준비운동으로 트레드밀에서 10 15분간 빠른 걷기 또는 가벼운 조깅 을 진행하였다. 측정 준비가 완료된 선수들에 한하여 무작위 선정 방식 (Randomized Trials)에 의해 선택된 번호에 따라 순서에 맞게 측정이 실시되었다. 진행 방법은 〈Fig. 2〉와 같다.

\section{측정 장비별 특징}

현재 다양한 버전의 윈게이트테스트 장비 중 국내에서 활용된 가장 초 기 모델은 한국스포츠정책과학원과 서울대학교가 공동 개발한 Wingate 834 model(DOS version)로 회전 당 총 4번 sensor 역할을 하는 magnet이 회전수를 계산하여 결과 값을 산출하는 방식이다. 이후 국내 도입된 Wingate $894 \mathrm{E}$ model(2.24 version)은 Sweden Monark 회사 에서 만든 측정 장비로 sensor 역할을 하는 magnet이 1개 있으며, 이를 통하여 한 바퀴의 회전수가 계산되어 수치화 된다. 894E model(3.3.0.0 version)은 magnet이 6개 있으며, 이를 통하여 한 바퀴가 계산되고 마 지막으로 894E model(3.2.1.0 version) 또한 6개의 magnet을 통하여 한 바퀴가 계산되고 수치화된다.

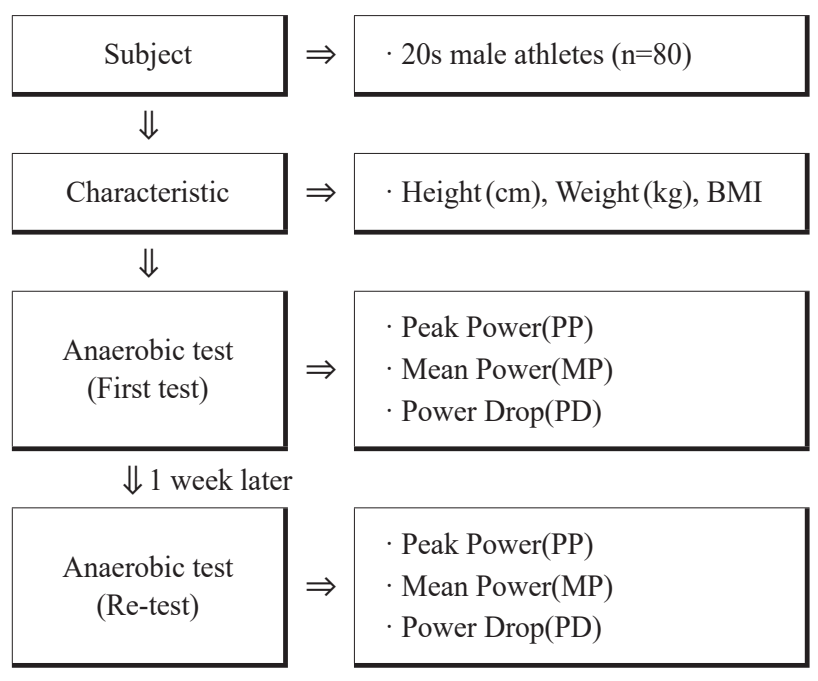

Fig. 1. Laboratory process 


\begin{tabular}{|c|c|c|c|c|c|c|c|c|c|}
\hline \multirow{3}{*}{ Warm-up } & \multirow{5}{*}{$\Rightarrow$} & \multicolumn{7}{|c|}{ Main-program } & \multirow{3}{*}{ Cool-down } \\
\hline & & & & & & & & $\mathrm{D}$ & \\
\hline & & Device & Rest & Device & Rest & Device & Rest & Device & \\
\hline \multirow{2}{*}{$\begin{array}{l}\text { Light jog or } \\
\text { Power walk } \\
(10 \sim 15 \mathrm{~min})\end{array}$} & & $\begin{array}{c}\text { DOS } \\
\text { ver }\end{array}$ & $\operatorname{Tr} 60^{\prime}$ & $\begin{array}{c}3.2 .1 .0 \\
\text { ver }\end{array}$ & $\operatorname{Tr} 60^{\prime}$ & $\begin{array}{c}2.24 \\
\text { ver }\end{array}$ & $\operatorname{Tr} 60^{\prime}$ & $\begin{array}{c}3.3 .0 .0 \\
\text { ver }\end{array}$ & \multirow{2}{*}{$\begin{array}{l}\text { Light jog or } \\
\text { Power walk } \\
\text { (10 15min) }\end{array}$} \\
\hline & & (win) & (int) & (win) & (int) & (win) & (int) & (win) & \\
\hline
\end{tabular}

※ ver : version, win : wingate 30 s(all out), $\mathrm{Tr}$ : treadmill running, int: $\dot{\mathrm{VO}}_{2} \max 50 \%$

Fig. 2. Experimental process

\section{자료 분석}

윈게이트테스트의 기기별 변인의 타당도를 확인하기 위해 SPSS(Ver.17) 를 활용하였으며 통계적 유의수준은 .05로 설정하였다. 타당도 검사는 기준 검사인 Wingate 834(DOS version)와 나머지 신규 장비인 2.24 version, 3.3.0.0 version, 3.2.1.0 version의 측정 장비의 적률상관계 수를 산출하여 검증하였다.

검사 및 재검사에 따른 신뢰도 검증은 1 주일 간격으로 2 회 측정한 결 과를 토대로 피어슨 상관계수를 산출하였다. 또한 4 가지 버전의 변인 (최고파워, 평균파워, 파워드롭률)을 상호변환 할 수 있도록 단순회귀분 석을 실시하여 추정식을 구하였다. 모든 통계적 유의수준은 .05로 설정 하였다.

\section{연구결과}

\section{버전별 변인들의 타당도 검증}

SPSS를 활용하여 종류별 윈게이트테스트 평균파워의 절댓값(Watt)과 상댓값 $(\mathrm{W} / \mathrm{kg})$ 은 적률상관계수를 이용하여 산출하였다(Table 2). 각 기 기별 평균파워의 절댓값과 상댓값은 모두 상관성(p〈.01)이 있는 것으로 나타났다. A 버전은 다른 모든 기기들과 높은 상관성이 있는 것으로 나 타났으며, 그 중 $\mathrm{A}$ 버전과 $\mathrm{B}$ 버전의 절댓값의 상관이 가장 높은 것으로 나 타났다. 뒤를 이어 $\mathrm{C}$ 와 $\mathrm{D}$ 버전이 높은 것으로 나타났다. 상댓값의 평균 파워는 $\mathrm{A}$ 버전과 $\mathrm{B}$ 버전이 가장 높은 것으로 나타났으며, 이후 $\mathrm{D}$ 버전과 $\mathrm{C}$ 버전의 순으로 높은 상관이 있는 것으로 나타났다.

각 기기별 최고파워 절댓값(Watt)유의한 상관성(p<.01)이 있는 것으 로 나타났다(Table 3). 그 중 $\mathrm{A}$ 버전과 $\mathrm{D}$ 버전의 상관성이 제일 높은 것으 로 나타났으며, 뒤를 이어 $\mathrm{B}$ 버전과 $\mathrm{C}$ 버전이 높은 것으로 나타났다. 상댓 값(Watt $/ \mathrm{kg})$ 의 경우에서도 유의한 상관성 $(\mathrm{p}<.05)$ 이 있는 것으로 나타났 으며, 그 중 $\mathrm{A}$ 버전과 $\mathrm{B}$ 버전의 상관성이 가장 높은 것으로 나타났다. 뒤 를 이어 $\mathrm{C}$ 버전과 $\mathrm{D}$ 버전의 순으로 나타났다.

각 기기별 파워드롭률(\%)의 경우 모두 상관성(p〈.01)이 있는 것으로 나타났다(Table 4). A 버전은 다른 모든 기기들과 높은 상관성이 있는 것으로 나타났으며, 그 중 $\mathrm{A}$ 버전과 $\mathrm{D}$ 버전의 상관이 가장 높은 것으로 나 타났다. 뒤를 이어 C와 B버전이 높은 것으로 나타났다.

\section{버전별 변인들의 신뢰도 검증}

검사-재검사를 통한 신뢰도 검증을 위해 피험자들은 1 주일 간격으로 2 회 측정을 진행하였으며, 참여 선수 80 명 중 36 명만이 반복측정에 참여
Table 2. Correlation Analysis of Mean Power

\begin{tabular}{|c|c|c|c|c|c|c|}
\hline \multirow{2}{*}{\multicolumn{3}{|c|}{ Variables }} & \multicolumn{4}{|c|}{ Mean Power } \\
\hline & & & A & B & $\mathrm{C}$ & $\mathrm{D}$ \\
\hline \multirow{8}{*}{$\begin{array}{l}\text { Mean } \\
\text { Power }\end{array}$} & \multirow{2}{*}{ A } & Watt & 1 & & & \\
\hline & & $\mathrm{W} / \mathrm{kg}$ & 1 & & & \\
\hline & \multirow{2}{*}{ B } & Watt & $.912 * *$ & 1 & & \\
\hline & & $\mathrm{W} / \mathrm{kg}$ & $.730 * *$ & 1 & & \\
\hline & \multirow{2}{*}{$\mathrm{C}$} & Watt & $.879 * *$ & $.909 * *$ & 1 & \\
\hline & & $\mathrm{W} / \mathrm{kg}$ & $.644 * *$ & $.752 * *$ & 1 & \\
\hline & \multirow{2}{*}{$\mathrm{D}$} & Watt & $.827 * *$ & $.848 * *$ & $.841 * *$ & 1 \\
\hline & & $\mathrm{W} / \mathrm{kg}$ & $.684^{* *}$ & $.697^{* *}$ & $.685^{* *}$ & 1 \\
\hline
\end{tabular}

※ A: DOS version, B: 2.24 version, C: 3.3 .0 .0 version, D: 3.2 .1 .0 version, W: watt, **: $\mathrm{p}<.05, * *: \mathrm{p}<.01$

Table 3. Correlation Analysis of Peak Power

\begin{tabular}{|c|c|c|c|c|c|c|}
\hline \multirow{2}{*}{\multicolumn{3}{|c|}{ Variables }} & \multicolumn{4}{|c|}{ Peak Power } \\
\hline & & & A & $\mathrm{B}$ & $\mathrm{C}$ & $\mathrm{D}$ \\
\hline \multirow{8}{*}{$\begin{array}{c}\text { Peak } \\
\text { Power }\end{array}$} & \multirow{2}{*}{$\mathrm{A}$} & Watt & 1 & & & \\
\hline & & $\mathrm{W} / \mathrm{kg}$ & 1 & & & \\
\hline & \multirow{2}{*}{ B } & Watt & $.860 * *$ & 1 & & \\
\hline & & $\mathrm{W} / \mathrm{kg}$ & $.544^{* *}$ & 1 & & \\
\hline & \multirow{2}{*}{$\mathrm{C}$} & Watt & $.753 * *$ & $.772 * *$ & 1 & \\
\hline & & $\mathrm{W} / \mathrm{kg}$ & $.539 * *$ & $.534 * *$ & 1 & \\
\hline & \multirow{2}{*}{$\mathrm{D}$} & Watt & $.934^{* *}$ & $.825^{* *}$ & $.668 * *$ & 1 \\
\hline & & $\mathrm{W} / \mathrm{kg}$ & $.320 * *$ & $.247 *$ & $.366^{*}$ & 1 \\
\hline
\end{tabular}

※ A: DOS version, B: 2.24 version, C: 3.3 .0 .0 version, D: 3.2.1.0 version, W: watt, $* *: \mathrm{p}<.05, * *: \mathrm{p}<.01$

Table 4. Correlation Analysis of Power Drop

\begin{tabular}{c|c|cccc}
\hline \multicolumn{2}{c|}{ Variables } & \multicolumn{4}{c}{ Power Drop (\%) } \\
\cline { 3 - 5 } \multicolumn{2}{c}{} & A & B & C & D \\
\hline \multirow{2}{*}{$\begin{array}{c}\text { Power } \\
\text { Drop }\end{array}$} & A & 1 & & & \\
$(\%)$ & B & $.646^{* *}$ & 1 & & \\
& C & $.702 * *$ & $.588^{*} *$ & 1 & 1 \\
\hline
\end{tabular}

※ A: DOS version, B: 2.24 version, C: 3.3.0.0 version, D: 3.2.1.0 version, ${ }^{* *}: \mathrm{p}<.05, * *: \mathrm{p}<.01$ 
하였으며, 이중 35 명의 신뢰도를 검증하였다. 결과는 〈Table 5〉와 같다.

버전별 검사를 반복 측정하여 신뢰도를 검증한 결과 모든 변인에 서 높은 상관성이 있는 것으로 나타났다. 그 중 평균파워 절댓값(Watt) 의 신뢰도가 가장 높았으며, $\mathrm{A}$ 버전 평균파워(Watt)〉 $\mathrm{A}$ 버전 최고파워 (Watt)> D버전 최고파워(Watt) $>\mathrm{A}$ 버전 평균파워(Watt)〉, C버전 최고파 워(Watt)> D버전 평균파워(Watt) 순으로 높게 나타났다. B버전의 파워 드롭률은 가장 낮은 신뢰도가 나타났지만 유의한 상관성이 있는 것으로
나타났다. 또한 평균 및 최고파워의 절댓값에 비해 상댓값의 신뢰도가 비교적 낮게 나타났다.

\section{버전별 변인들의 상호변환 추정식 검증}

각 버전별 결과에 대한 오차범위를 최소화하기 위한 과정으로 평균파워 절댓값, 평균파워 상댓값, 최고파워 절댓값, 최고파워 상댓값 및 파워드 롭률의 추정식을 개발하였다. 결과는 〈Table 6 8〉과 같다.

Table 5. Pearson Correlation Coefficients

\begin{tabular}{|c|c|c|c|c|c|c|c|}
\hline \multicolumn{3}{|c|}{ Variables } & Mean & $\mathrm{SD}$ & $\mathrm{n}$ & $\mathrm{r}$ & $\mathrm{p}$ \\
\hline \multirow{8}{*}{$\begin{array}{l}\text { Mean Power } \\
\text { (Watt) }\end{array}$} & \multirow{2}{*}{ A } & $\mathrm{T}_{1}$ & 494.76 & 104.42 & \multirow{2}{*}{35} & \multirow{2}{*}{.932} & \multirow{2}{*}{$<.001$} \\
\hline & & $\mathrm{T}_{2}$ & 487.28 & 93.06 & & & \\
\hline & \multirow{2}{*}{ B } & $\mathrm{T}_{1}$ & 517.24 & 105.79 & \multirow{2}{*}{35} & \multirow{2}{*}{.944} & \multirow{2}{*}{$<.001$} \\
\hline & & $\mathrm{T}_{2}$ & 527.08 & 114.28 & & & \\
\hline & \multirow{2}{*}{$\mathrm{C}$} & $\mathrm{T}_{1}$ & 510.33 & 117.92 & \multirow{2}{*}{35} & \multirow{2}{*}{.888} & \multirow{2}{*}{$<.001$} \\
\hline & & $\mathrm{T}_{2}$ & 519.45 & 114.75 & & & \\
\hline & \multirow{2}{*}{$\mathrm{D}$} & $\mathrm{T}_{1}$ & 687.41 & 141.08 & \multirow{2}{*}{34} & \multirow{2}{*}{.838} & \multirow{2}{*}{$<.001$} \\
\hline & & $\mathrm{T}_{2}$ & 691.74 & 137.46 & & & \\
\hline \multirow{8}{*}{$\begin{array}{c}\text { Mean Power } \\
(\mathrm{W} / \mathrm{kg})\end{array}$} & \multirow{2}{*}{ A } & $\mathrm{T}_{1}$ & 6.51 & .706 & \multirow{2}{*}{35} & \multirow{2}{*}{.932} & \multirow{2}{*}{$<.001$} \\
\hline & & $\mathrm{T}_{2}$ & 6.29 & .660 & & & \\
\hline & \multirow{2}{*}{ B } & $\mathrm{T}_{1}$ & 6.80 & .753 & \multirow{2}{*}{35} & & \\
\hline & & $\mathrm{T}_{2}$ & 6.76 & .639 & & .944 & $<.001$ \\
\hline & $\mathrm{C}$ & $\mathrm{T}_{1}$ & 6.71 & .912 & & & \\
\hline & C & $\mathrm{T}_{2}$ & 6.80 & .943 & 35 & .888 & $<.001$ \\
\hline & $\mathrm{D}$ & $\mathrm{T}_{1}$ & 9.25 & .743 & 34 & 838 & $<001$ \\
\hline & D & $\mathrm{T}_{2}$ & 8.89 & .823 & 34 & .858 & $<.001$ \\
\hline & A & $\mathrm{T}_{1}$ & 756.03 & 164.05 & 35 & & \\
\hline & A & $\mathrm{T}_{2}$ & 741.25 & 140.49 & 35 & .932 & $<.001$ \\
\hline & & $\mathrm{T}_{1}$ & 696.33 & 186.48 & & & \\
\hline Peak Power & B & $\mathrm{T}_{2}$ & 694.46 & 155.02 & 35 & .799 & $<.001$ \\
\hline (Watt) & $\mathrm{C}$ & $\mathrm{T}_{1}$ & 777.34 & 226.54 & 35 & 862 & $<001$ \\
\hline & C & $\mathrm{T}_{2}$ & 836.78 & 215.70 & 53 & .802 & $<.001$ \\
\hline & $\mathrm{D}$ & $\mathrm{T}_{1}$ & 1137.39 & 255.75 & 35 & 891 & 002 \\
\hline & D & $\mathrm{T}_{2}$ & 1089.66 & 199.49 & 35 & .891 & .002 \\
\hline & $A$ & $\mathrm{~T}_{1}$ & 9.95 & 1.109 & & & \\
\hline & A & $\mathrm{T}_{2}$ & 9.57 & 0.996 & 34 & .625 & $<.001$ \\
\hline & $B$ & $\mathrm{~T}_{1}$ & 9.15 & 1.327 & 32 & 773 & $<001$ \\
\hline Peak Power & B & $\mathrm{T}_{2}$ & 8.91 & 0.867 & 32 & .173 & $<.001$ \\
\hline (W/kg) & $C$ & $\mathrm{~T}_{1}$ & 10.22 & 1.752 & 34 & 768 & $<001$ \\
\hline & $C$ & $\mathrm{~T}_{2}$ & 10.95 & 1.773 & 34 & .700 & .001 \\
\hline & & $\mathrm{T}_{1}$ & 15.31 & 1.347 & & & \\
\hline & $\mathrm{D}$ & $\mathrm{T}_{2}$ & 14.00 & 1.194 & 32 & .531 & .002 \\
\hline & $A$ & $\mathrm{~T}_{1}$ & 57.23 & 5.82 & 33 & 649 & $<001$ \\
\hline & A & $\mathrm{T}_{2}$ & 56.04 & 6.46 & 35 & .049 & $<.001$ \\
\hline & B & $\mathrm{T}_{1}$ & 56.84 & 8.74 & 35 & 461 & 005 \\
\hline Power Drop & & $\mathrm{T}_{2}$ & 57.61 & 7.76 & JJ & .401 & .005 \\
\hline$(\%)$ & $C$ & $\mathrm{~T}_{1}$ & 66.15 & 11.32 & & & \\
\hline & C & $\mathrm{T}_{2}$ & 69.52 & 9.37 & 34 & .655 & $<.001$ \\
\hline & & $\mathrm{T}_{1}$ & 65.42 & 7.08 & & & \\
\hline & $\mathrm{D}$ & $\mathrm{T}_{2}$ & 63.34 & 7.83 & 34 & .634 & $<.001$ \\
\hline
\end{tabular}

※ A: DOS version, B: 2.24 version, C: 3.3.0.0 version, D: 3.2.1.0 version, T1: first test, T2: second test, W: watt 
Table 6. Simple Regression Analysis on Mean Power \& Equations

\begin{tabular}{|c|c|c|c|c|c|c|c|c|}
\hline & Category & B & St.Error & $\beta$ & $\mathrm{t}(\mathrm{p})$ & $\mathrm{R}^{2}$ & SEE & Equations \\
\hline \multirow{6}{*}{$\frac{\mathrm{A}}{\text { (Watt) }}$} & (constant) & 81.682 & 19.669 & & $4.153(<.001)$ & \multirow{2}{*}{.799} & \multirow{2}{*}{35.83} & \multirow{6}{*}{$\begin{array}{l}\cdot A=0.784 \times B+81.682 \\
\cdot A=0.695 \times C+128.328 \\
\cdot A=0.580 \times D+88.257\end{array}$} \\
\hline & B MP & .784 & .038 & .894 & $20.622(<.001)$ & & & \\
\hline & (constant) & 128.328 & 28.790 & & $4.457(<.001)$ & \multirow{2}{*}{.601} & \multirow{2}{*}{41.40} & \\
\hline & C_MP & .695 & .058 & .775 & $11.907(<.001)$ & & & \\
\hline & (constant) & 88.257 & 24.705 & & $3.572(.001)$ & & & \\
\hline & D_MP & .580 & .036 & .841 & $16.061(<.001)$ & .707 & 42.97 & \\
\hline \multirow{6}{*}{$\begin{array}{c}\text { B } \\
\text { (Watt) }\end{array}$} & (constant) & 19.177 & 24.108 & & $.795(.428)$ & \multirow{2}{*}{.799} & \multirow{2}{*}{40.88} & \multirow{6}{*}{$\begin{array}{l}\cdot B=1.020 \times A+19.177 \\
\cdot B=0.915 \times C+50.489 \\
\cdot B=0.717 \times D+24.866\end{array}$} \\
\hline & A_MP & 1.020 & .049 & .894 & $20.622(<.001)$ & & & \\
\hline & (constant) & 50.489 & 27.364 & & $1.845(.068)$ & \multirow{2}{*}{.747} & \multirow{2}{*}{39.61} & \\
\hline & C_MP & .915 & .055 & .864 & $16.584(<.001)$ & & & \\
\hline & (constant) & 24.866 & 23.949 & & $1.038(.301)$ & \multirow{2}{*}{.802} & \multirow{2}{*}{47.48} & \\
\hline & D_MP & .717 & .034 & .896 & $20.933(<.001)$ & & & \\
\hline \multirow{6}{*}{$\begin{array}{c}\mathrm{C} \\
\text { (Watt) }\end{array}$} & (constant) & 83.455 & 34.276 & & $2.435(.017)$ & \multirow{2}{*}{.601} & \multirow{2}{*}{46.178} & \multirow{6}{*}{$\begin{array}{l}\cdot \mathrm{C}=0.865 \times \mathrm{A}+83.455 \\
\cdot \mathrm{C}=0.817 \times \mathrm{B}+82.685 \\
\cdot \mathrm{C}=0.592 \times \mathrm{D}+99.309\end{array}$} \\
\hline & A_MP & .865 & .073 & .775 & $11.907(<.001)$ & & & \\
\hline & (constant) & 82.685 & 24.880 & & $3.323(.001)$ & 747 & 37416 & \\
\hline & B_MP & .817 & .049 & .864 & $16.584(<.001)$ & .147 & 37.416 & \\
\hline & (constant) & 99.309 & 32.902 & & $3.018(.003)$ & 605 & 47058 & \\
\hline & D_MP & .592 & .049 & .778 & $11.992(<.001)$ & .005 & $4 / .058$ & \\
\hline \multirow{6}{*}{$\begin{array}{c}\mathrm{D} \\
(\text { Watt })\end{array}$} & (constant) & 90.200 & 36.865 & & $2.447(.016)$ & \multirow{2}{*}{.707} & & \\
\hline & A_MP & 1.219 & .076 & .841 & $16.061(<.001)$ & & 62.29 & . $D=1219 \times A+90200$ \\
\hline & (constant) & 107.998 & 28.231 & & $3.826(<.001)$ & 802 & 5034 & . $\mathrm{D}=1120 \times \mathrm{B}+107008$ \\
\hline & B_MP & 1.120 & .053 & .896 & $20.933(<.001)$ & .802 & 59.34 & \\
\hline & (constant) & 159.157 & 42.178 & & $3.773(<.001)$ & 605 & 6181 & $\cdot \mathrm{D}=1.021 \times \mathrm{C}+159.157$ \\
\hline & C_MP & 1.021 & .085 & .778 & $11.992(<.001)$ & .005 & 01.81 & \\
\hline & (constant) & 1.554 & .434 & & $3.581(.001)$ & 536 & 180 & \\
\hline & B_MP & .720 & .064 & .732 & $11.316(<.001)$ & .536 & .480 & \\
\hline A & (constant) & 3.604 & .484 & & $7.444(<.001)$ & & & $\cdot A=0.720 \times B+1.554$ \\
\hline$(\mathrm{W} / \mathrm{kg})$ & C_MP & .422 & .070 & .503 & $6.015(<.001)$ & .253 & .56 & $\begin{array}{l}\cdot A=0.422 \times C+3.604 \\
\cdot A=0.627 \times D+0.705\end{array}$ \\
\hline & (constant) & .705 & .538 & & $1.309(.193)$ & 504 & 10 & \\
\hline & D_MP & .627 & .059 & .710 & $10.674(<.001)$ & .504 & .49 & \\
\hline & (constant) & 1.994 & .426 & & $4.683(<.001)$ & 536 & 10 & \\
\hline & A_MP & .744 & .066 & .732 & $11.316(<.001)$ & .536 & .49 & \\
\hline B & (constant) & 2.930 & .455 & & $6.444(<.001)$ & 117 & 52 & $\cdot \mathrm{B}=0.744 \times \mathrm{A}+1.994$ \\
\hline$(\mathrm{W} / \mathrm{kg})$ & C_MP & .570 & .066 & .646 & $8.673(<.001)$ & .417 & .52 & $\begin{array}{l}\cdot B=0.570 \times C+2.930 \\
\cdot B=0.588 \times D+1.421\end{array}$ \\
\hline & (constant) & 1.421 & .601 & & $2.363(.020)$ & 121 & 54 & \\
\hline & D_MP & .588 & .066 & .649 & $8.943(<.001)$ & .421 & .54 & \\
\hline & (constant) & 2.968 & .650 & & $4.565(<.001)$ & 253 & 67 & \\
\hline & A_MP & .599 & .100 & .503 & $6.015(<.001)$ & .253 & .67 & \\
\hline $\mathrm{C}$ & (constant) & 1.860 & .581 & & $3.202(.0002)$ & 117 & 50 & $\cdot \mathrm{C}=0.599 \times \mathrm{A}+2.968$ \\
\hline$(\mathrm{W} / \mathrm{kg})$ & B_MP & .732 & .084 & .646 & $8.673(<.001)$ & .417 & .59 & $\begin{array}{l}\cdot \mathrm{C}=0.732 \times \mathrm{B}+1.860 \\
\cdot \mathrm{C}=0.563 \times \mathrm{D}+1.694\end{array}$ \\
\hline & (constant) & 1.694 & .769 & & $2.203(.030)$ & 300 & 651 & \\
\hline & D_MP & 563 & .083 & .548 & $6.743(<.001)$ & .300 & .651 & \\
\hline & (constant) & 3.959 & .487 & & $8.126(<.001)$ & 504 & 556 & \\
\hline & A_MP & .804 & .075 & .710 & $10.674(<.001)$ & .504 & .556 & \\
\hline $\mathrm{D}$ & (constant) & 4.260 & .546 & & $7.804(<.001)$ & & 601 & $\begin{array}{l}\cdot \mathrm{D}=0.804 \times \mathrm{A}+3.959 \\
\cdot \mathrm{D}=0716 \times \mathrm{B}+4260\end{array}$ \\
\hline & B_MP & .716 & .080 & .649 & $8.943(<.001)$ & .421 & .601 & $\begin{array}{l}\cdot \mathrm{D}=0.716 \times \mathrm{B}+4.260 \\
\cdot \mathrm{D}=0.533 \times \mathrm{C}+5.523\end{array}$ \\
\hline & (constant) & 5.523 & .546 & & $10.112(<.001)$ & 300 & 633 & \\
\hline & C_MP & .533 & .079 & .548 & $6.743(<.001)$ & .300 & .033 & \\
\hline
\end{tabular}

※ A: DOS version, B: 2.24 version, C: 3.3.0.0 version, D: 3.2.1.0 version, W: watt, MP: mean power, SEE: standard error of estimate 
Table 7. Simple Regression Analysis on Peak Power \& Equations

\begin{tabular}{|c|c|c|c|c|c|c|c|c|}
\hline & Category & $\mathrm{B}$ & St.Error & $\beta$ & $\mathrm{t}($ sig) & $\mathrm{R}^{2}$ & SEE & Equations \\
\hline \multirow{6}{*}{$\begin{array}{c}\text { A } \\
\text { (Watt) }\end{array}$} & (constant) & 225.002 & 45.366 & & $4.960(<.001)$ & \multirow{2}{*}{.600} & \multirow{2}{*}{69.11} & \multirow{6}{*}{$\begin{array}{l}\cdot A=0.759 \times B+225.002 \\
\cdot A=0.342 \times C+479.923 \\
\cdot A=0.567 \times D+120.911\end{array}$} \\
\hline & B_PP & .759 & .065 & .775 & $11.683(<.001)$ & & & \\
\hline & (constant) & 479.923 & 60.871 & & $7.884(<.001)$ & \multirow{2}{*}{.178} & \multirow{2}{*}{97.58} & \\
\hline & C_PP & .342 & .081 & .422 & $4.217(<.001)$ & & & \\
\hline & (constant) & 120.911 & 45.712 & & $2.645(.010)$ & \multirow{2}{*}{.681} & \multirow{2}{*}{54.13} & \\
\hline & D_PP & .567 & .042 & .825 & $13.379(<.001)$ & & & \\
\hline \multirow{6}{*}{$\begin{array}{c}\text { B } \\
\text { (Watt) }\end{array}$} & (constant) & 97.992 & 51.177 & & $1.915(.059)$ & \multirow{2}{*}{.600} & \multirow{2}{*}{70.56} & \multirow{6}{*}{$\begin{array}{l}\cdot B=0.791 \times A+97.992 \\
\cdot B=0.503 \times C+296.894 \\
\cdot B=0.567 \times D+61.874\end{array}$} \\
\hline & A_PP & .791 & .068 & .775 & $11.683(<.001)$ & & & \\
\hline & (constant) & 296.894 & 45.662 & & $6.502(<.001)$ & 424 & 9001 & \\
\hline & C_PP & .503 & .062 & .651 & $8.132(<.001)$ & .424 & 90.01 & \\
\hline & (constant) & 61.874 & 60.631 & & $1.020(.031)$ & 520 & 7742 & \\
\hline & D_PP & .567 & .057 & .721 & $9.881(<.001)$ & .520 & 11.42 & \\
\hline \multirow{6}{*}{$\begin{array}{c}\mathrm{C} \\
\text { (Watt) }\end{array}$} & (constant) & 357.535 & 91.570 & & $3.905(<.001)$ & \multirow{2}{*}{.178} & \multirow{2}{*}{120.56} & \multirow{6}{*}{$\begin{array}{l}\cdot \mathrm{C}=0.522 \times \mathrm{A}+357.535 \\
\cdot \mathrm{C}=0.842 \times \mathrm{B}+166.497 \\
\cdot \mathrm{C}=0.365 \times \mathrm{D}+329.165\end{array}$} \\
\hline & A_PP & .522 & .124 & .422 & $4.217(<.001)$ & & & \\
\hline & (constant) & 166.497 & 69.452 & & $2.397(.019)$ & \multirow{2}{*}{.424} & \multirow{2}{*}{116.48} & \\
\hline & B_PP & .842 & .104 & .651 & $8.132(<.001)$ & & & \\
\hline & (constant) & 329.165 & 106.843 & & $3.081(.003)$ & 131 & 13368 & \\
\hline & D_PP & .365 & .102 & .362 & $3.562(.001)$ & .131 & 133.08 & \\
\hline \multirow{6}{*}{$\begin{array}{c}\mathrm{D} \\
\text { (Watt) }\end{array}$} & (constant) & 196.435 & 65.783 & & $2.986(.004)$ & \multirow{2}{*}{.681} & 7872 & \\
\hline & A_PP & 1.200 & .090 & .825 & $13.379(<.001)$ & & & \\
\hline & (constant) & 445.627 & 61.769 & & $7.214(<.001)$ & 520 & 0852 & $\cdot \mathrm{D}=1.200 \times \mathrm{A}+196.435$ \\
\hline & B_PP & .918 & .093 & .721 & $9.881(<.001)$ & .520 & 98.52 & 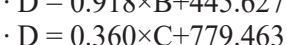 \\
\hline & (constant) & 779.463 & 72.723 & & $10.718(<.001)$ & 131 & 13271 & \\
\hline & C_PP & .360 & .101 & .362 & $3.562(.001)$ & & 132.71 & \\
\hline & (constant) & 5.494 & .753 & & $7.300(<.001)$ & 212 & 87 & \\
\hline & B_PP & .478 & .082 & .492 & $5.845(<.001)$ & .242 & .81 & \\
\hline A & (constant) & 8.032 & .470 & & $17.080(<.001)$ & 134 & 93 & $\begin{array}{l}\cdot A=0.478 \times B+5.494 \\
\cdot A=0175 \times C+8.032\end{array}$ \\
\hline$(\mathrm{W} / \mathrm{kg})$ & C_PP & .175 & .044 & .367 & $4.017(<.001)$ & & & $\begin{array}{l}A=0.15 \times C+8.032 \\
\cdot A=0.509 \times D+2.421\end{array}$ \\
\hline & (constant) & 2.421 & .741 & & $3.265(.001)$ & 489 & 60 & \\
\hline & D_PP & .509 & .050 & .700 & $10.126(<.001)$ & .489 & .09 & \\
\hline & (constant) & 4.156 & .860 & & $4.833(<.001)$ & 242 & 89 & \\
\hline & A_PP & .507 & .087 & .492 & $5.845(<.001)$ & & & \\
\hline $\mathrm{B}$ & (constant) & 7.097 & .464 & & $15.289(<.001)$ & 175 & 01 & $\cdot B=0.507 \times A+4.156$ \\
\hline$(\mathrm{W} / \mathrm{kg})$ & C_PP & .200 & .043 & .418 & $4.644(<.001)$ & $.1 / 5$ & .91 & $\begin{aligned} B & =0.200 \times C+1.091 \\
B & =0.264 \times D+5.300\end{aligned}$ \\
\hline & (constant) & 5.300 & 1.065 & & $4.975(<.001)$ & 114 & 96 & \\
\hline & D_PP & .264 & .072 & .338 & $3.648(<.001)$ & & & \\
\hline & (constant) & 3.005 & 1.899 & & $1.583(.117)$ & 124 & 105 & \\
\hline & A_PP & .768 & .191 & .367 & $4.017(<.001)$ & .134 & 1.95 & \\
\hline $\mathrm{C}$ & (constant) & 2.542 & 1.745 & & $1.457(.148)$ & 175 & 191 & $\begin{aligned} \cdot \mathrm{C} & =0.768 \times \mathrm{A}+3.005 \\
\cdot \mathrm{C} & =0.874 \times \mathrm{B}+2542\end{aligned}$ \\
\hline$(\mathrm{W} / \mathrm{kg})$ & B_PP & .874 & .188 & .418 & $4.644(<.001)$ & & & $\begin{array}{l}\mathrm{C}=0.8 / 4 \times \mathrm{B}+2.34 \mathrm{~L} \\
\mathrm{C}=0.119 \times \mathrm{D}+8.941\end{array}$ \\
\hline & (constant) & 8.941 & 2.242 & & $3.988(<.001)$ & 006 & 205 & \\
\hline & D_PP & .119 & .152 & .077 & $.779(.438)$ & .000 & 2.05 & \\
\hline & (constant) & 5.170 & .943 & & $5.480(<.001)$ & 489 & 05 & \\
\hline & A_PP & .961 & .095 & .700 & $10.126(<.001)$ & & & \\
\hline $\mathrm{D}$ & (constant) & 10.700 & 1.097 & & $9.751(<.001)$ & 114 & 123 & $\cdot \mathrm{D}=0.961 \times \mathrm{A}+5.170$ \\
\hline$(\mathrm{W} / \mathrm{kg})$ & B_PP & .434 & .119 & .338 & $3.648(<.001)$ & .114 & 1.23 & 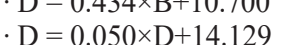 \\
\hline & (constant) & 14.129 & .703 & & $20.100(<.001)$ & 006 & 134 & \\
\hline & C_PP & .050 & .065 & .077 & $.779(.438)$ & .006 & 1.34 & \\
\hline
\end{tabular}

※ A: DOS version, B: 2.24 version, C: 3.3.0.0 version, D: 3.2.1.0 version, W: watt, PP: peak power, SEE: standard error of estimate 
Table 8. Simple Regression Analysis on Power Drop \& Equations

\begin{tabular}{|c|c|c|c|c|c|c|c|c|}
\hline & Category & B & St.Error & $\beta$ & $\mathrm{t}(\mathrm{sig})$ & $\mathrm{R}^{2}$ & SEE & Equations \\
\hline \multirow{6}{*}{$\begin{array}{c}\text { A } \\
(\%)\end{array}$} & (constant) & 37.595 & 3.574 & & $10.519(<.001)$ & \multirow{2}{*}{.213} & \multirow{2}{*}{5.41} & \multirow{6}{*}{$\begin{array}{l}\cdot A=0.335 \times B+37.595 \\
\cdot A=0.157 \times C+46.218 \\
\cdot A=0.534 \times D+22.130\end{array}$} \\
\hline & B_PD & .335 & .062 & .461 & $5.427(<.001)$ & & & \\
\hline & (constant) & 46.218 & 3.608 & & $12.810(<.001)$ & \multirow{2}{*}{.076} & \multirow{2}{*}{5.74} & \\
\hline & C_PD & .157 & .053 & .276 & $2.952(.004)$ & & & \\
\hline & (constant) & 22.130 & 4.259 & & $5.196(<.001)$ & \multirow{2}{*}{.382} & \multirow{2}{*}{4.78} & \\
\hline & D_PD & .534 & .065 & .618 & $8.202(<.001)$ & & & \\
\hline \multirow{6}{*}{$\begin{array}{c}\text { B } \\
(\%)\end{array}$} & (constant) & 21.230 & 6.680 & & $3.178(.002)$ & \multirow{2}{*}{.213} & \multirow{2}{*}{7.45} & \multirow{6}{*}{ 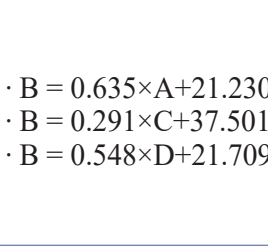 } \\
\hline & A_PD & .635 & .117 & .461 & $5.427(<.001)$ & & & \\
\hline & (constant) & 37.501 & 4.722 & & $7.942(<.001)$ & \multirow{2}{*}{.142} & \multirow{2}{*}{7.69} & \\
\hline & C_PD & .291 & .069 & .376 & $4.202(<.001)$ & & & \\
\hline & (constant) & 21.709 & 6.234 & & $3.482(.001)$ & \multirow{2}{*}{.230} & \multirow{2}{*}{7.41} & \\
\hline & D_PD & .548 & .096 & .479 & $5.725(<.001)$ & & & \\
\hline \multirow{6}{*}{$\begin{array}{c}\mathrm{C} \\
(\%)\end{array}$} & (constant) & 39.637 & 9.364 & & $4.233(<.001)$ & \multirow{2}{*}{.076} & \multirow{2}{*}{10.10} & \multirow{6}{*}{$\begin{array}{l}\cdot \mathrm{C}=0.484 \times \mathrm{A}+39.637 \\
\cdot \mathrm{C}=0.486 \times \mathrm{B}+39.496 \\
\cdot \mathrm{C}=0.263 \times \mathrm{D}+50.210\end{array}$} \\
\hline & A_PD & .484 & .164 & .276 & $2.952(.004)$ & & & \\
\hline & (constant) & 39.496 & 6.673 & & $5.919(<.001)$ & \multirow{2}{*}{.142} & \multirow{2}{*}{9.94} & \\
\hline & B_PD & .486 & .116 & .376 & $4.202(<.001)$ & & & \\
\hline & (constant) & 50.210 & 9.202 & & $5.456(<.001)$ & \multirow{2}{*}{.031} & \multirow{2}{*}{10.65} & \\
\hline & D_PD & .263 & .141 & .177 & $1.864(.065)$ & & & \\
\hline \multirow{6}{*}{$\begin{array}{c}\mathrm{D} \\
(\%)\end{array}$} & (constant) & 24.415 & 4.985 & & $4.897(<.001)$ & \multirow{2}{*}{.382} & \multirow{2}{*}{5.54} & \multirow{6}{*}{$\begin{array}{l}\cdot \mathrm{D}=0.715 \times \mathrm{A}+24.415 \\
\cdot \mathrm{D}=0.419 \times \mathrm{B}+40.786 \\
\cdot \mathrm{D}=0.119 \times \mathrm{C}+56.903\end{array}$} \\
\hline & A_PD & .715 & .087 & .618 & $8.202(<.001)$ & & & \\
\hline & (constant) & 40.786 & 4.230 & & $9.642(<.001)$ & \multirow{2}{*}{.230} & \multirow{2}{*}{6.48} & \\
\hline & B_PD & .419 & .073 & .479 & $5.725(<.001)$ & & & \\
\hline & (constant) & 56.903 & 4.335 & & $13.127(<.001)$ & \multirow{2}{*}{.031} & \multirow{2}{*}{7.16} & \\
\hline & C_PD & .119 & .064 & .177 & $1.864(.065)$ & & & \\
\hline
\end{tabular}

※ A: DOS version, B: 2.24 version, C: 3.3.0.0 version, D: 3.2.1.0 version, W: watt, PD: power drop, SEE: standard error of estimate

\section{논의}

본 연구는 버전별 윈게이트 장비의 결과값 차이로 인하여 활용하는 기기 의 결과값을 표준화시키기 위해 국가대표 및 엘리트 선수 80명을 대상 으로 현재 국내에 도입된 4 가지 형태의 윈게이트테스트 장비의 기기별 호환성에 대한 타당도 및 신뢰도를 알아보기 위해 진행하였다. 이는 초 창기 도입된 DOS 버전을 시작으로 각기 다른 버전의 기기들이 현장에 서 선수들의 체력 평가를 위해 활용되고 있으나 기기별 값이 달라 통일 된 결과해석에 제한이 있는게 현실이다. 따라서, 과거부터 현재까지 축 적되어진 결과를 비교·분석하여 빅데이터가 구축된다면 우수선수 선발, 종목별 훈련 프로그램의 구성 및 효과 검증의 기초자료로 활용될 것으로 여겨진다. 그러므로 본 연구에서는 기기별 결과들의 호환 가능성을 확인 하고 신뢰도와 타당도 검증을 통해 윈게이트 기기별 상호 변환추정식을 제시하고자 한다.

본 연구에서는 서로 다른 버전의 평균파워에 대한 결과들을 기초로 장 비의 교차 타당성을 검증한 결과 비교적 높은 상관 $(\mathrm{r}=.644 \sim .912)$ 이 있 는 것으로 나타났다. 특히, 측정 결과에 대한 절댓값은 $r=.827 \sim .912$ 로 매우 높게 나타났으며, 상댓값은 $r=.644 \sim .752$ 까지 절댓값에 비해 다 소 낮게 나타났지만 유의한 결과임을 알 수 있다. 동일 또는 유사 장비를 이용한 검사-재검사 관찰 방법은 선행 검사를 통한 학습효과로 인하여 개연성이 존재함에도 불구하고 결과에 대한 높은 상관이 있어 타당도가 높은 기기임을 알 수 있다. 최고파워 검사에서는 절댓값의 경우 $r=.668$
.934까지로 나타나 매우 높은 관련성이 있었으나, 상댓값의 경우 r= $.247 \sim .544$ 인 것으로 나타나 비교적 낮은 상관이 있음을 알 수 있다. 특 히 $\mathrm{D}(3.2 .1 .0)$ 버전과 다른 버전과의 검사-재검사 결과를 비율로 나타내 면 약 33 40\%의 차이가 있는 것으로 나타났으며, 이는 시간의 제약 또 는 장비고장으로 인하여 사전·사후의 기기가 변동된다면 결과 값의 신 뢰성이 심각하게 훼손될 수 있음을 알 수 있다. Fry et al.(1991)은 적절 한 훈련 강도의 설정이 선수들의 경기력 향상에 도움이 될 것으로 보고 하고 있으며, 이런 훈련 강도는 정확한 체력 측정에서 얻어진 결과를 기 초로 구성되어야 이상적인 체력 개선을 유도할 수 있는 것으로 제시하고 있다(Lehmann et al., 1992). 부정확한 체력 측정은 선수들의 훈련 프 로그램 구성에 따른 과훈련(overtraining) 또는 상해(injury)의 원인으로 작용하며(Halson \& Jeukndrup, 2004; Meeusen et al., 2004), 국가대 표와 같이 중요한 선수 선발을 위해서는 정확한 측정과 평가가 동반되 어야 할 것이다. 파워드롭률에서도 $r=.558 \sim .804$ 의 높은 상관이 있는 것으로 나타났지만, 이를 기기별 비율로 계산 시 12 14\%의 차이가 발 생하였다. 이에 본 연구에서 각 기기별 결과 값을 보완할 수 있는 추정식 을 개발하였으며, 장비 이상 또는 시기 및 측정인원에 따른 호환이 불가 피할 경우 추정식 적용을 통하여 기기에 따른 결과 차이를 보완할 수 있 을 것으로 여겨진다. 이처럼 체력측정에서 정확한 측정방법을 기반으로 일관된 결과 값이 도출되어야만 정확한 운동처방이 이루어지게 된다. 특 히, 스포츠 현장에서 요구되는 빅데이터(Big Data)를 적절히 활용하기 위해서는 과거와 현재의 데이터를 표준화된 도구로 종합적인 분석이 필 
요하다. 따라서 측정기기의 버전이 다양하게 변화되어 왔다면 결과 값에 대한 일관된 표준화가 선행되어야 올바른 해석이 가능할 것이다. 측정기 기가 발전할수록 그 결과 값도 차이가 발생할 수 있기 때문이다.

본 연구에서 진행된 기기별 신뢰도 검증에서 측정결과는 $r=.461 ~$ $.944(\mathrm{p}<.05)$ 인 것으로 나타났으며, 결과 값에 대한 비율 환산 시 차이 는 0.2 8.5\%까지 인 것으로 나타났다. 선행연구에서는 태권도 선수를 대상으로 실시된 연구에서 최고파워 상댓값(사전 11.48 \pm 1.63 , 사후 $11.56)$ 과 평균파워 상댓값(6.24 \pm 1.17 , 사후 $6.40 \pm 1.21)$ 의 각 결과차 가 1 2.5\% 미만인 것으로 나타났다(Hwang et al., 2020). 엘리트 대학 축구 선수를 대상으로 실시된 연구에서는 사전·사후 무산소성 최고파 워(Watt $/ \mathrm{kg}$ )가 1 3\%미만의 차이가 있는 것으로 나타났다(Lee et al., 2019). 국외연구에서도 최고파워 $(W a t t / \mathrm{kg})$ 가 사전 $11.76 \pm 1.99$, 사 후 $11.82 \pm 1.62$, 평균파워 $(\mathrm{Watt} / \mathrm{kg})$ 는 사전 $5.79 \pm 0.86$, 사후 $5.71 \pm$ 0.87 로 나타나 각 $0.5 \sim 1.3 \%$ 의 차이가 있는 것으로 나타났다(Ramezani Ahmadi et al., 2020). Bicer(2020)의 연구에서는 엘리트 배구 선수들 의 체력 측정 결과 무산소성 최고파워가 $0.5 \%(\mathrm{Watt}), 4.7 \%(\mathrm{Watt} / \mathrm{kg})$ 의 차이가 있는 것으로 나타났으며, 평균파워는 $4 \%(\mathrm{Watt}), 5 \%(\mathrm{Watt} / \mathrm{kg})$ 가 있는 것으로 나타났다. 본 연구에서 4 개의 윈게이트 버전별 결과값의 평 균을 낸 결과, 절댓값 평균파워(1.5\%), 상댓값 평균파워(2.3\%), 절댓값 최고파워(3.5\%), 상댓값 최고파워(5.5\%), 파워드롭률(2.9\%)로 반복측정 전후 차이가 나타났다.

기기별 본 연구결과에서는 평균파워(Watt)는 도스 버전 기기를 기 준으로 $\mathrm{B}$ 버전(+6.3\%), C버전(+4.9\%), $\mathrm{D}$ 버전(+40.4\%)이 각각 높았 다. 특히 $\mathrm{D}$ 버전과의 차이가 컸다. 상대평균파워 $(\mathrm{Watt} / \mathrm{kg})$ 에서는 $\mathrm{B}$ 버전 (+5.9\%), C버전(+5.9\%), D버전(+41.7\%)으로 역시 $\mathrm{D}$ 버전의 값이 높았 다. 결과적으로 A, B, C 버전 간 무산소 평균파워에서는 약 5-6\% 차이 가 있었으나 $\mathrm{D}$ 버전은 $40 \sim 42 \%$ 높아 해석에 주의가 따른다. 최고파워 (Watt)는 도스 버전 기기를 기준으로 B버전(-7.1\%), C버전(+7.8\%), D 버전(+48.8\%)의 값을 보였다. 특히, $\mathrm{D}$ 버전과의 차이가 높게 나타났으 며, 상대최고파워(Watt $/ \mathrm{kg}$ )에서는 $\mathrm{B}$ 버전(-7.5\%), $\mathrm{C}$ 버전(+8.5\%), D버 전(+50.2\%)으로 역시 $\mathrm{D}$ 버전의 값이 가장 높았다. 결과적으로 $\mathrm{A}, \mathrm{B}, \mathrm{C}$ 버전 간 무산소성 최고파워에서는 약 -7 9\% 차이가 있었으나 $\mathrm{D}$ 버전은 49 50\% 높아 해석에 주의가 따른다.

따라서 선행연구들과의 결과 비교 시에도 본 연구의 측정 신뢰도는 높 은 것을 알 수 있었으며, 이는 서로 다른 버전의 윈게이트 측정 장비를 활용하여 측정하더라도 상호 변환이 가능하여 표준화된 값으로 신뢰할 수 있는 평가 자료로 활용될 수 있을 것으로 기대된다.

\section{결론 및 제언}

\section{1. 결론}

본 연구의 목적은 전문 운동선수들의 무산소성파워를 검사하는데 일반 적으로 널리 사용하는 윈게이트 테스트기기의 버전별 값이 달라 그 타당 성과 신뢰성을 살펴보고, 버전 간 상호 변환추정식을 제시하는데 있었 다. 이를 위한 남자 엘리트 및 국가대표 선수 80명을 대상으로 4가지 버 전에 대한 윈게이트 측정을 진행하였다. 실험 시 주요 측정변인은 무산 소성 파워변인인 최고파워(peak power), 평균파워(average power), 파워드롭률(power drop rate)을 관찰하였다. 결과 값에 대한 기기별 타 당성과 신뢰성을 확인하기 위해 상관관계를 실시하였으며, 장비에 따른 결과 값의 호환을 위해 단순회귀분석을 활용하여 윈게이트 기기 버전 간 상호 변환추정식을 개발하였다.

결론적으로 타당성 및 신뢰성 검사에서는 모든 기기에서 통계적으로 유의한 결과(p<.05)가 있는 것으로 나타났다.

이상의 결과를 종합해 볼 때, 전문 운동선수들을 대상으로 무산소성 파워를 측정한 결과, 윈게이트테스트 기기별 버전이 상이하여도 상호 변 환추정식을 활용한다면 결과 값의 보정과 표준화를 통해 올바른 결과 해 석에 도움이 될 것이다. 빅데이터를 활용 시 본 추정식을 활용한다면 큰 도움이 될 수 있을 것이다.

\section{2. 제언}

본 연구에서는 20 대 남자선수들을 대상으로 윈게이트 기기의 4 가지 버 전 별 상호 변환 추정식을 개발하였다. 추후 연구에서는 각 버전별 추 정식에 대한 세분화 작업을 위해 성별 및 나이를 고려한 다양한 피험 자의 측정·분석과 최신버전인 엑스칼리버(Excalibur Sports, LODE, Netherlands)와의 관련 변환추정식 연구도 필요할 것으로 여겨진다. 


\section{참고문헌}

Attia, A., Hachana, Y., Chaabene, H., Gaddour, A., Neji, Z., Shephard, R. J., Chelly, M. S. (2014). Reliability and validity of a 20-s alternative to the wingate anaerobic test in team sport male athletes. PLoS ONE, 9(12), 1-10.

Baker, J. S., McCormick, M. C., Robergs, R. A. (2010). Interaction among skeletal muscle metabolic energy systems during intense exercise. Journal of Nutrition and Metabolism, 221-233.

Bar-Or. O. (1987). The wingate anaerobic test: an update on methodology, reliability and validity. Sports Medicine, 4(6), 381-394.

Bar-Or, O., Dotan, R., Inbar, O., Rothstein, A., Karlsson, J., Tesch, P. (1980). Anaerobic capacity and muscle fiber type distribution in man. International Journal of Sports Medicine, 1(2), 82-85.

Beneke, R., Pollmann, C., Blief, I., Leithäuser, R. M., Hütler, H. (2002). How anaerobic is the wingate anaerobic test for humans?. European Journal of Applied Physiology, 87(4-5), 388-392.

Bicer, M. (2020). The effect of an eight-week strength training program supported with functional sports equipment on male volleyball players' anaerobic and aerobic power. Science \& Sports, 36(2), 137(e1)-137(e9).

Bigland-Ritchie, B., Woods, J. J. (1984). Changes in muscle contractile properties and neural control during human muscular fatigue. Muscle and Nerve, 7(9), 691-699.

Bogdanis, G. C., Nevill, M. E., Lakomy, H. K. A., Boobis, L. H. (1998). Power output and muscle metabolism during and following recovery from 10 and $20 \mathrm{~s}$ of maximal sprint exercise in humans. Acta Physiologica Scandinavica, 163(3), 261-272.

Bompa, T. O. (1999). Periodization Training for Sports. USA: Human Kinetics.

Fry, P. W., Morton, A. R., Keast, D. (1991). Over training in athletes. Sports Medicine, 12(1), 32-65.

Grant, M. C., Robergs, R., Baird, M. F., Baker, J. S. (2014). The effect of prior upper body exercise on subsequent wingate performance. BioMed Research International, Article ID 329328.

Halson, S. L., Jeukendrup, A. E. (2004). Does over training exist?. Sports Medicine, 34(14), 967-981.

Harvey, L., Bousson, M., McLellan, C., Lovell, D. (2017). The effect of previous wingate performance using one body region on subsequent wingate performance using a different body region. Journal of Human Kinetics, 56(1), 119-126.

Hwang, W. G., Park, K. M., Kang, S. H. (2020). Effect of plyometric training on anaerobic power and isokinetic muscular function in taekwondo demonstration players. Korean Journal of Sports Science, 29(2), 1321-1331.

Inbar, O., Bar-or, O., Skinner, J. S. (1996). The wingate anaeorbic test. Human Kinetics, Champaign, III.

Kavaliauskas, M., Aspe, R. R., Babraj, J. (2015). High-intensity cycling training: The effect of work-to-rest intervals on running performance measures. Journal of Strength and Conditioning Research, doi: 10.1519/JSC.0000000000000868.

Kendall, B. J. (2017). The acute effects of static stretching compared to dynamic stretching with and without an active warm up on anaerobic performance. International Journal of Exercise Science, 10(1), 53-61.

Laurent, C. M., Meyers, M. C., Robinson, C. A., \& Green, J. M. (2007). Cross-validation of the 20 - versus 30 -s wingate anaerobic test. European Journal of Applied Physiology, 100(6), 645-651.

Lee, Y. K., Song, Y. J., Park, J. Y. (2019). Effect of 8weeks of power training program on leg strength, anaerobic power and blood lactate concentration of elite soccer players. Korean Journal of Sports Science, 28(1), 1327-1341.

Lehmann, M., Baumgartl, P., Wiesenack, C., Seidel, A., Baumann, H., Fischer, S. (1992). Training-over training: influence of a defined increase in training volume vs training intensity on performance, catechol amines and some metabolic parameters in experienced middle- and long-distance runners. European Journal of Applied Physiology and Occupational Physiology, 64(2), 169-177.

Lewis, E. J. H., Stucky, F., Radonic, P. W., Metherel, A. H., Wolever, T. M. S., Wells, G. D. (2017). Neuromuscular adaptations to sprint interval training and the effect of mammalian omega-3 fatty acid supplementation. European Journal of Applied Physiology, 117(3), 469-482.

Meeusen, R., Nederhof, E., Buyse, L., Roelands, B., De Schutter, G., Piacentini, M. F. (2010). Diagnosing overtraining in athletes using the two-bout exercise protocol. British Journal of Sports Medicine, 44(9), 642-648.

Raci, K., Burak, C. Y., Hakan, K., Mitat, K., Gulfem, E. (2017). Effect of serial caffeine mouth rinse on wingate anaerobic performance. Journal of Physical Education \& Sports Sciences, 15(4), 191-196.

Ramezani Ahmadi, A., Mohammadshahi, M., Alizadeh, A., Ahmadi Angali, K., Jahanshahi, A. (2020). Effects of vitamin D3 supplementation for 12 weeks on serum levels of anabolic hormones, anaerobic power, and aerobic performance in active male subjects: A randomized, double-blind, placebo-controlled trial. European Journal of Sport Science, 20(10), 1355-1367.

Ren, J. M., Hultman, E. (1989). Regulation of glycogenolysis in human skeletal muscle. Journal of Applied Physiology, 67(6), 2243-2248.

Richmond, S. R., Whitman, S. A., Acree, L. S., Olson, B. D., Carper, M. J., Godard, M. P. (2011). Power output in trained male and female cyclists during the wingate test with increasing flywheel resistance. Journal of Exercise Physiology, 14(5), 46-53.

Vandewalle, H., Pers, G., Monod, H. (1987). Standard anaerobic exercise tests. Sports Medicine, 4(4), 268-289.

Weinstein, Y., Bediz, C., Dotan, R., Falk, B. (1998). Reliability of peaklactate, heart rate, and plasma volume following the wingate test. Medicine and Science in Sports and Exercise, 30(9), 1456-1460.

Zupan, M. F., Arata, A. W., Dawson, L. H., Wile, A. L., Payn, T. L., Hannon, M. E. (2009). Wingate anaerobic test peak power and anaerobic capacity classifications for men and women intercollegiate athletes. Journal of Strength and Conditioning Research, 23(9), 2598-2604. 


\section{윈게이트 기기 버전 별 무산소성 파워변인의 신뢰도와 타당도 분석을 통한 상호변환 추정식 개발}

성봉주 ${ }^{1}$, 고병구 ${ }^{1}$, 이광규 ${ }^{2}$

1 한국스포츠정책과학원 수석연구위원

2 전주기전대학 운동재활과 교수

[목적] 본 연구는 무산소성 파워 측정을 위한 윈게이트 테스트 기기별 결과값의 타당성 및 신뢰성을 분석해 기기간 추정 식을 제시하는데 있다.

[방법] 연구 참가자들은 배드민턴(n=15), 레슬링 $(n=19)$, 역도(n=16), 육상 $(n=16)$ 종목의 엘리트 남자 선수 66명과 국가 대표 남자 복싱선수 14 명을 포함하여 총 80 명을 대상으로 하였다. 검사는 국내 도입된 윈게이트 테스트 장비 중 총 4 가 지 형태 (Type A: DOS version, Type B: version 2.24, Type C: 3.3.0.0, Type D: version 3.2.1.0)로 체중별 운동부하 를 달리하여 30 초씩 반복측정을 실시하였다. 각 기기별 반복기간은 1 주일로 하였다. 자료 분석은 타당도 검사를 위해 측 정 장비의 적률상관계수를 산출하였으며, 검사 및 재검사에 따른 신뢰도 검사를 위해 피어슨 상관계수를 산출하였다. 기 기별 결과값의 상호변환을 위해 단순회귀분석을 이용하여 추정식을 구하였다.

[결과] 타당도 검증에서는 각 기기별 평균파워의 절댓값과 상댓값(p<.01), 최고파워의 절댓값(p<.01)과 상댓값(p<.05), 파워드롭률(p〈.01)에서 상관성이 있는 것으로 나타났다. 검사와 재검사에 대한 신뢰도 검사에서도 높은 상관이 있는 것 으로 나타났다(p<.01). 또한, 기기별 평균파워 및 최고파워의 상댓값과 절댓값, 파워드롭률의 추정식을 산출하여 제시하 였다.

[결론] 이상의 결과를 종합하면, 본 연구에서 개발된 추정식을 이용하여 각기 다른 버전의 무산소 윈게이트 결과값의 상 호변환이 가능할 것으로 여겨진다.

주요어

윈게이트 무산소성 검사, 최고파워, 평균파워, 파워드롭률, 추정식 